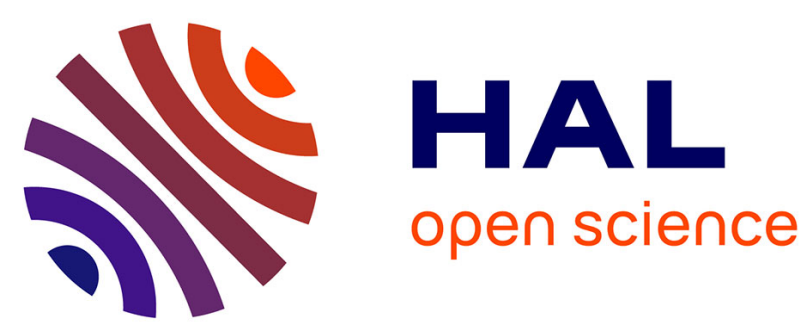

\title{
PRODUCTION OF DOUBLY CORE EXCITED CONFIGURATIONS IN C4+ PROJECTILES THROUGH RESONANT TRANSFER EXCITATION
}

J .M. Anthony, S .M. Shafroth, Malika Benhenni, E . N. Strait, T. Zouros, L. Hendrick, D. Peterson

\section{To cite this version:}

J .M. Anthony, S .M. Shafroth, Malika Benhenni, E . N. Strait, T. Zouros, et al.. PRODUCTION OF DOUBLY CORE EXCITED CONFIGURATIONS IN C4+ PROJECTILES THROUGH RESONANT TRANSFER EXCITATION. Journal de Physique Colloques, 1987, 48 (C9), pp.C9-301-C9-306. 10.1051/jphyscol:1987954 . jpa-00227372

\section{HAL Id: jpa-00227372 https://hal.science/jpa-00227372}

Submitted on 1 Jan 1987

HAL is a multi-disciplinary open access archive for the deposit and dissemination of scientific research documents, whether they are published or not. The documents may come from teaching and research institutions in France or abroad, or from public or private research centers.
L'archive ouverte pluridisciplinaire HAL, est destinée au dépôt et à la diffusion de documents scientifiques de niveau recherche, publiés ou non, émanant des établissements d'enseignement et de recherche français ou étrangers, des laboratoires publics ou privés. 


\title{
PRODUCTION OF DOUBLY CORE EXCITED CONFIGURATIONS IN $C^{4}+$ PROJECTILES THROUGH RESONANT TRANSFER EXCITATION ${ }^{(1)}$
}

\author{
J.M. ANTHONY (2), S.M. SHAFROTH, M. BENHENNI, E.N. STRAIT(3), \\ T.J.M. ZOUROS*, I.D. HENDRICK* ${ }^{*}$ and D.M. PETERSON** \\ University of North Carolina, Chapel Hill, NC 27514, Triangle \\ Universities Nuclear Laboratory, Durham, NC 27706, U.S.A. \\ *Kansas State University, Manhattan, KS 66506, U.S.A. \\ **Francis Marion College, Florence, SC 29501, U.S.A.
}

\begin{abstract}
Projectile K-Auger electron production cross sections have been measured for $C^{4+}+$ ions in 3 to $8 \mathrm{MeV}$ collisions with atomic $\mathrm{He}, \mathrm{Ne}$, and molecular Hydrogen targets at lab observation angles of 9.60 to 10.60. The K-Auger electron spectra predominantly result from decays of $L i$-like excited states and are interpreted as single electron capture to the metastable 1 s $2 \mathrm{~s}$ ${ }^{3} \mathrm{~S}$ component of the incident beam. High resolution $K-L L$ Auger spectra show that capture into $2 s$ is suppressed by the presence of the $2 s$ spectator electron. The formation of single and double core excited Li-like $2 D$ configurations are interpreted in part as resonant transfer and excitation with the ground state and metastable components respectively. Also, the data shows a much stronger production of the $2 s^{2} 2 p 2 P$ configuration through NTE for Ne than for the He target.
\end{abstract}

1. Introduction When stripping is used to increase the charge of fast Carbon ions, excited configurations produced in the process usually decay promptly (eg. $\tau \approx 1.1 \times 10^{-12} \mathrm{sec}$. for $1 \mathrm{~s} 2 \mathrm{p} 1 \mathrm{P}$ ions). However, for two-electron ions the metastable $1 \mathrm{~s} 2 \mathrm{~s} 3 \mathrm{~S}$ configuration $\left(\tau=2.01 \times 10^{-2} \mathrm{sec}^{1}\right)$ arrives on target without decay. Measurements of the fraction of vacancy bearing two-electron ions at various incident energies can be found in the literature. Their measurement is based on projectile to target $\mathrm{K}$-shell vacancy transfer. $1 \mathrm{~s} 2 \mathrm{~s} 3 \mathrm{~S}$ ions have been used to study partial cross sections for capture to specific $n$ or $n, 1$ shells $1,2(n \geq 2)$. When our Auger electron production cross sections are divided by published values of the fraction of 1 s $2 s$ $3 \mathrm{~S}$ ions in the incident beam 1 , we find that the energy dependance of these inferred electron capture cross sections agrees with a classical Bohr-Linhardt calculation ${ }^{3}$ for capture by $\mathrm{C}^{4+}\left(1 \mathrm{~s}^{2}\right)$ ions. However, the data overpredict the calculation and we attribute this, in part, to differences in screening by $1 s^{2}$ and 1 s 2 s ions. The high resolution K-LL Auger spectrum is composed of decays of five Li-like configurations. Three are thought to be formed directly by electron capture into the $2 \mathrm{p}$ subshell and one by capture into the 2 s subshell. Auger electron production from the decay of the $1 s 2 \mathrm{p} 22 \mathrm{D}$ configuration exhibits a maximum intensity at a collision energy of $5 \mathrm{MeV}$, and agrees well with theoretical calculations for resonant transfer and excitation (RTE). Also, a maximum in the cross sections at $6 \mathrm{MeV}$ for unresolved transitions containing capture to $n \geq 3$ as well as the doubly core excited $2 s^{2} 2 \mathrm{p} 2 \mathrm{P}$ and $2 \mathrm{~s} 2 \mathrm{p}^{2} 2 \mathrm{D}$ configuration decaying to either $1 \mathrm{~s} 2 \mathrm{~s} 1 \mathrm{~S}$ or ${ }^{3} \mathrm{~S}$, agrees with the predicted collision energy for a maximum in the RTE cross section.

Electron transfer excitation cross sections are needed in the fields of thermonuclear fusion, heavy ion storage ring and $x$-ray laser design, as well as for astrophysical model calculations. In particular, RTE is closely related to dielectronic recombination - a significant energy loss mechanism in tokamak plasmas. DR, in which a fast free electron is captured by a slow ion, can be viewed as the inverse Auger process. The probability for DR depends strongly on the kinetic energy of the free electron and, if the time reversal analogy is correct, we expect this dependance to reflect the kinetic energy distribution of electrons emitted during Auger decay. The RTE process occurs in ion atom collisions when the velocity of the ion is varied so that the kinetic energy (in the ion's rest frame) of a loosely bound target electron appears to pass through a DR type resonance.

\footnotetext{
(1) Supported in part by US DOE under contract No. DE-AS05-78ER06027

(2) Also North Carolina state University, Raleigh, NC 27695, U.S.A.

(3) Permanent address : Macalester College, St, Paul, MN 55105. U.S.A.
} 
Recently, two experimenters have reported the observation of RTE using the technique of $0^{\circ}$ Auger spectroscopy. Swenson et. al. 4 studied the $\mathrm{O}^{5+}+$ He system and found resonances in the production of $1 \mathrm{~s} 2 \mathrm{~s} 2 \mathrm{p}^{2}{ }^{1} \mathrm{D}$ and ${ }^{3} \mathrm{D}$ excited states. Itoh et. al..$^{5}$ reported a similar resonance in the production of the $2 \mathrm{p}^{2} 1 \mathrm{D}$ state for the symmetric $\mathrm{He}^{+}+\mathrm{He}$ collision system. In these experiments a target electron is captured by the ion which emerges from the collision complex in an excited configuration. Since no measurement is made on the target fragment, we know only that it is at least singly ionized, but may also be excited and multiply ionized. When the captured electron is emitted during the Auger decay, a new channel for target ionization is opened:

$$
\mathrm{P}^{\mathrm{Q}+}\left({ }^{2 \mathrm{~S}+1} \mathrm{~L}\right)+\mathrm{T} \underset{\text { R T E }}{\rightarrow} \mathrm{P}^{(\mathrm{Q}-1)+}\left({ }^{2 \mathrm{~S}+1} \mathrm{~L}\right)+\underset{\text { Augerdecay }}{\mathrm{T}^{+}} \underset{\mathrm{P}^{\mathrm{Q}}}{\rightarrow}+\mathrm{T}^{+}+\mathrm{e}^{-}\left(\mathrm{E}_{\text {Aug }}\right)
$$

where ${ }^{2 S+1} \mathrm{~L}$ is the incident ionic configuration, ${ }^{2 S+1} \mathrm{~L}$ is the excited configuration formed through $\mathrm{RTE}$, $\mathrm{T}$ is the target, and $\mathrm{T}^{+}$refers to the system composed of the remaining target electrons and nucleus. Destructive interference between this process and direct target ionization has been discussed by Swenson et. al. to explain anomalies in their K-LL Auger spectrum.

As in DR, a maximum in the RTE production probability occurs when the difference between the captured electron's kinetic energy (KE) and its initial binding energy to the target (B) becomes equal to the energy difference between the excited and incident configurations: $K E-B=E(2 S+1 L)-E(2 S+1 L)$. Examination of (1) shows that this occurs when the collision energy is: $\mathrm{E}_{\mathrm{RTE}}=\mathrm{M}_{\mathrm{ion}} / \mathrm{m}_{\text {clectron }}\left(\mathrm{E}_{\mathrm{Aug}}-\mathrm{B}\right)$. Brandt has shown that the momentum distribution of the bound target electron broadens the resonance as a result of orbital motion in the direction of the collision axis. This problem has been treated in the impulse approximation, and a method has been developed to relate DR to RTE using the bound electron's Compton profile6. 2. Experiment 10-30 $\mu \mathrm{A}$ currents of $\mathrm{C}$ - were produced in a sputter ion source, and accelerated by the Triangle Universities Nuclear Laboratory model FN tandem Van de Graaff. $\mathrm{C}^{4+}$ ions were then formed by post acceleration stripping and selected magnetically. The distance from post stripper foil to the target cell was 9 meters. After collimation, the ions passed through a $25 \mathrm{~mm}$ long target cell with 2 stages of differential pumping, and were collected in a suppressed Faraday cup. Periodic checks of target current without gas in the cell showed no detectable enhancement or neutralization due to the gas. Pressure studies were done with Neon to insure single collision conditions. Projectile Auger yields were found to be linear up to $30 \mathrm{~m}$ Torr (39.5 $\mu \mathrm{bar})$.

Auger electrons were observed by the high resolution projectile electron spectrometer (HRPES). This electrostatic spectrometer has been described in detail elsewhere?. The normatization for absolute cross section was determined by measuring Neon $\mathrm{K}$-Auger electron yields for $3 \mathrm{MeV} \mathrm{H}+$ collisions and comparing with a published value for Ne $\mathrm{K}$-shell ionization. The length of the viewing region varied with observation angle, and is approximately $5 \mathrm{~mm}$.

Typical spectra are shown in figure 1. They have been background subtracted and transformed into the rest frame of the projectile. The improved resolution in figure $\mathrm{lb}$ was obtained by decelerating the electrons to $1 / 6$ of their lab frame energy before passing through the spectrometer ${ }^{8}$. Since the electron pass energy was not a constant for the various collision energies, the decelerated spectra were normalized by a deceleration efficiency factor determined at each collision energy: $\varepsilon_{\text {decel }}=$ Yield(decelerated)/Yield(undecelerated).

3. K-LL Auger Spectrum and Capture to $n=2$ Figure 2 a shows the total capture cross sections into all $n \geq 2$ shells of $1 \mathrm{~s} 2 \mathrm{~s}$. $3 \mathrm{~S}$ ions for the various targets, and includes all K-L Auger transitions (227.5 - 299 eV). The Hydrogen data was divided by two, in order to compare with the atomic cross sections for $\mathrm{He}$ and $\mathrm{Ne}$. Others 9 have found the ratio for capture from molecular and atomic Hydrogen targets to be 3.89, and we do not mean to attach any special significance to our proceedure. Figure $2 \mathrm{a}$ also shows Brandt's semiclassical calculation for the He target ${ }^{3}$ as the solid curve. As discussed above, the calculation underpredicts our data by a numerical factor of 4.5 .

Ratios of cross sections for capture into specific L-S coupled configurations by $1 \mathrm{~s}^{3} \mathrm{~s}^{3} \mathrm{~S}$ ions are shown in table 1. They were obtained from the doubly differential high resolution spectra similar to figure $1 \mathrm{~b}$. Capture into the $2 \mathrm{~s}$ sub-shell of metastable projectiles always results in the $1 \mathrm{~s} 2 \mathrm{~s}^{2} 2 \mathrm{~S}$, while capturc into the $2 \mathrm{p}$ sub-shell can result in the $1 \mathrm{~s}(2 \mathrm{~s} 2 \mathrm{p} 3 \mathrm{P}) 2 \mathrm{P}$; $1 \mathrm{~s}(2 \mathrm{~s} 2 \mathrm{p} 1 \mathrm{P}){ }^{2 \mathrm{P}}$; or $1 \mathrm{~s} 2 \mathrm{~s} 2 \mathrm{p} 4 \mathrm{P}$. The relative strengths of the $1 \mathrm{~s}\left(2 \mathrm{~s} 2 \mathrm{p}{ }^{3} \mathrm{P}\right) 2 \mathrm{P}$ and $1 \mathrm{~s}(2 \mathrm{~s} 2 \mathrm{p} 1 \mathrm{P})$ configurations indicate that

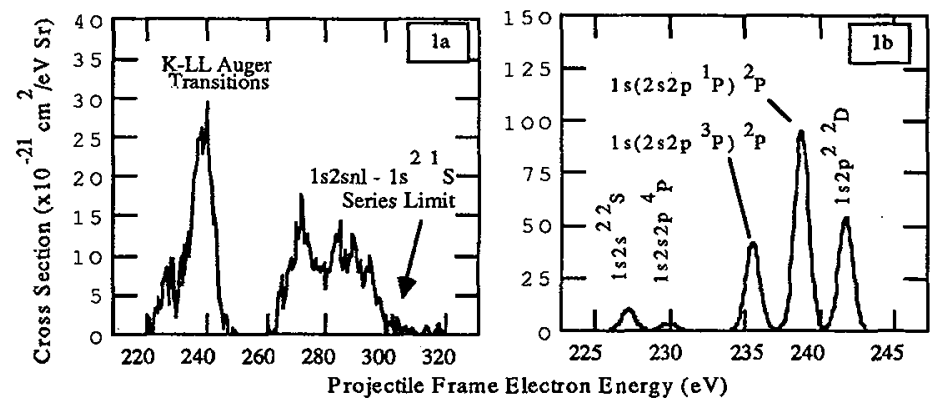

Figure $1 K-L(1 a)$ and $K-L L(1 b)$ Auger specirum of Carbon formed in $5 \mathrm{MeV}$ collisions of $\mathrm{C}^{4+}$ with Helium. The Gaussian fits to the raw spectra in $1 b$ shows improved resolution $(0.5 \%$ FWHM) resulting from decelerating Auger electrons before the analyzer. The excited states shown in $1 b$ decay to $1 s^{2} I S$. 

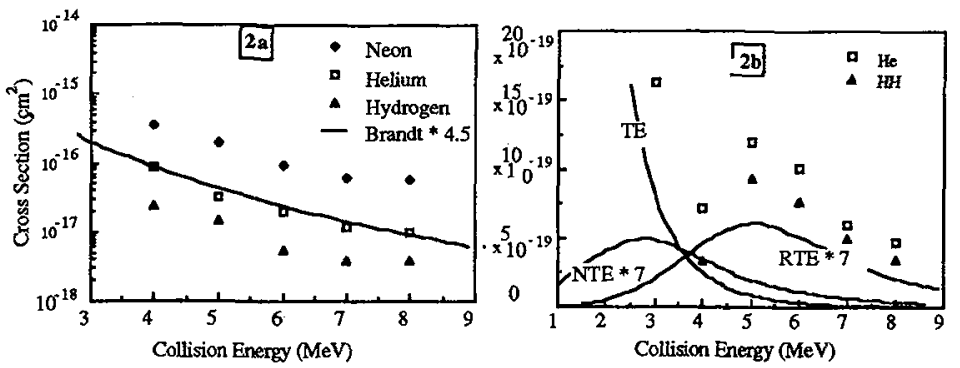

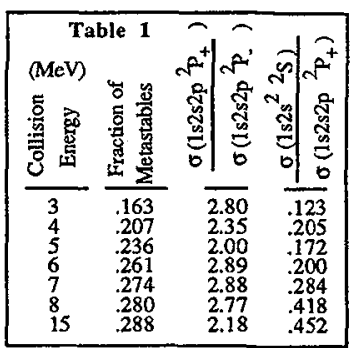

Figure 2 Infered cross sections for capture into all sub-shells with $n \geq 2$ by $1 s 2 s{ }^{3} \mathrm{~S}$ ions from $\mathrm{H}_{2}, \mathrm{He}$, and $\mathrm{Ne}$ targets is shown in $2 a$. (Auger production cross sections were divided by the fraction of metastables at each collision energy). Figure $2 b$ shows shows the $1 s 2 p^{2} 2 D-1 s^{2} 1 S$ Auger production cross section as well as various production schemes (Auger production cross sections were divided by the fraction of ground state ions at each collision energy). Table 1 Intensity fraction of metastable ions in the incident beam at the various collision energies (values were taken from reference 1, and statistical errors were $\sim \pm .06$ ). Also, experimental Auger production ratios for three configurations formed by capture into the $n=2$ shell of $C^{4+}$ in collisions with $H e$.

capture into the empty $2 \mathrm{p}$ sub-shell is statistical. From tables of fractional parentage coeficients 10 ;

and

$$
\begin{aligned}
& \left.\left.\left|<1 \mathrm{~s} 2 \mathrm{~s}^{3} \mathrm{~S}, 2 \mathrm{p}\right|\right\} 1 \mathrm{~s}\left(2 \mathrm{~s} 2 \mathrm{p}{ }^{1} \mathrm{P}\right){ }^{2} \mathrm{P}>\left.\right|^{2}=3\left|<1 \mathrm{~s} 2 \mathrm{~s}^{3} \mathrm{~S}, 2 \mathrm{p}\right|\right\} 1 \mathrm{~s}\left(2 \mathrm{~s} 2 \mathrm{p}{ }^{3} \mathrm{P}\right){ }^{2} \mathrm{P}>\left.\right|^{2} \\
& \left.\left.\left|<1 \mathrm{~s} 2 \mathrm{~s}^{3} \mathrm{~S}, 2 \mathrm{p}\right|\right\} 1 \mathrm{~s} 2 \mathrm{~s} 2 \mathrm{p}{ }^{4} \mathrm{P}>\left.\right|^{2}=\frac{4}{3}\left|<1 \mathrm{~s} 2 \mathrm{~s}^{3} \mathrm{~S}, 2 \mathrm{p}\right|\right\} 1 \mathrm{~s}\left(2 \mathrm{~s} 2 \mathrm{p}{ }^{1} \mathrm{P}\right){ }^{2} \mathrm{P}>\left.\right|^{2}
\end{aligned}
$$

This equation gives the statistical ratios for coupling the $1 \mathrm{~s} 2 \mathrm{~s}{ }^{3 \mathrm{~S}}$ preparent and $2 \mathrm{p}$ coparent to either $1 \mathrm{~s} 2 \mathrm{~s} 2 \mathrm{p} 2 \mathrm{P}$ or $1 \mathrm{~s} 2 \mathrm{~s} 2 \mathrm{p} 4 \mathrm{P}$ postparents. Specifying either the $(2 s 2 \mathrm{p} 1 \mathrm{P})$ or $(2 \mathrm{~s} 2 \mathrm{p} 3 \mathrm{P})$ intermediate coupling removes any ambiguity in the $1 \mathrm{~s} 2 \mathrm{~s} 2 \mathrm{p} 2 \mathrm{P}$ postparent. The director (1) ) leads from lower symmetry to higher symmetry. We find that the experimental ratio for capture into the different $1 \mathrm{~s} 2 \mathrm{~s} 2 \mathrm{p} 2 \mathrm{P}$ configurations is nearly equal to the ratio of $3: 1$ as predicted above.

The excited $1 \mathrm{~s} 2 \mathrm{p}^{2} 2 \mathrm{D}$ configuration cannot be formed directly by single electron capture to either component of the incident projectile beam. Instead, it is formed when a target electron is captured and an additional projectile electron is excited into a $2 p$ orbital during the same collision. The situation becomes even more complex when we consider that the excitation may result from the time varying potential of either the target nucleus, or the target electrons. The $1 s 2 \mathrm{p}^{2} 2 \mathrm{D}$ configuration can be formed from $1 \mathrm{~s} 2 \mathrm{~s} 3 \mathrm{~S}$ Carbon ions when capture into the $2 \mathrm{p}$ orbital is accompanied by $2 \mathrm{~s}-2 \mathrm{p}$ excitation. This channel is shown in figure $2 \mathrm{~b}$ as the monotonically decreasing curve. The probabilities $\mathrm{P}_{2 \mathrm{~s}-2 \mathrm{p}}(\mathrm{b})$ and $\mathrm{P}_{1 \mathrm{~s}-2 \mathrm{p}}(\mathrm{b})$ were calculated analytically in the semiclassical approximation with individually screened hydrogenic wave functions 11 . The calculation assumes a straight line trajectory for the projectile, and no target recoil. $\mathrm{P}_{\text {capt }}(\mathrm{b})$ was formulated by Brandt ${ }^{3}$ based on a two step Bohr-Lindhardt model. In the first step, an electron is released by the target when the target binding potential is overcome by the attractive potential of the projectile. Capture by the projectile can then occur if the distance from the projectile at the time of release is smaller than $R_{C}=2 q /\left(v_{\text {proj }}\right)^{2}$ (that is if the electron's kinetic energy is smaller than its potential energy in the field of the projectile). The TE curve is then calculated according to:

$$
\sigma_{\mathrm{TE}}\left(1 \mathrm{~s} 2 \mathrm{~s}^{3} \mathrm{~S} \rightarrow 1 \mathrm{~s} 2 \mathrm{p}^{22} \mathrm{D}\right)=2 \pi \int \mathrm{P}_{\text {exc }}^{2 \mathrm{~s}-2 \mathrm{p}}(\mathrm{b}) \mathrm{P}_{\text {capt }}^{2 \mathrm{p}}(\mathrm{b}) \mathrm{b} \text { db where } \mathrm{P}_{\text {capt }}^{2 \mathrm{p}}(\mathrm{b}) \approx \frac{1}{2} \mathrm{P}_{\text {ca }}
$$

Since the calculation does not give partial probabilities for capture into specific orbitals of the projectile, we have used the $1 / \mathrm{n}^{3}$ scaling law in (3) and assume that capture into $2 \mathrm{~s}$ is negligible to estimate that $\sim 1 / 2$ of all capture is into a $2 \mathrm{p}$ orbital.

The $1 \mathrm{~s} 2 \mathrm{p}^{2} 2 \mathrm{D}$ can also be formed in collisions with $1 \mathrm{~s}^{2}$ ground state projectiles. In this case, a $1 \mathrm{~s}-2 \mathrm{p}$ excitation accompanies capture into the $2 \mathrm{p}$ orbital. This process has been considered before and is known as non resonant transfer excitation (NTE). Since the incident ion is now in the $1 \mathrm{~s}^{2}$ state, the statistical ratio of capture into $2 \mathrm{p}$ to capture into all $\mathrm{n} \geq 2$. is $1 / 3$ :

$$
\sigma_{\mathrm{NTE}}\left(1 \mathrm{~s}^{22} \mathrm{~S} \rightarrow 1 \mathrm{~s} 2 \mathrm{p}^{22} \mathrm{D}\right)=2 \pi \int \mathrm{P}_{\mathrm{exc}}^{1 \mathrm{~s}-2 \mathrm{p}}(\mathrm{b}) \mathrm{P}_{\mathrm{capt}}^{2 \mathrm{p}}(\mathrm{b}) \mathrm{b} \text { db with } \mathrm{P}_{\text {capt }}^{2 \mathrm{p}}(\mathrm{b})=\frac{1}{3} \mathrm{P}_{\text {capt }}(\mathrm{b})
$$

The NTE calculation is shown in figure $2 b$ and peaks at a collision energy of $\sim 3 \mathrm{MeV}$.

One final mechanism for producing the $1 s 2 \mathrm{p}^{2} 2 \mathrm{D}$ configuration is through RTE. This production mechanism is similar to NTE in that a 1s-2p excitation occurs when a $1 s^{2} 1 \mathrm{~S}$ ion captures an electron into a $2 \mathrm{p}$ orbital. However, the excitation is now the result of internal conversion of the captured electron's kinetic energy. As shown in figure $2 b$, $a$ maximum in the RTE production for the $C^{4+}\left(1 s^{2} 1 S\right)+$ He collision system is predicted at $\sim 5 \mathrm{MeV}$ in agreement with the data. The RTE calculation was provided by McLaughlin 12 , and uses the method outlined by Brandt ${ }^{6}$ for folding the target electron's Compton profile with calculated DR cross sections. 
4. Hyper-Satelites and Capture to $n \geq 3$ High resolution spectra for Carbon $K$-Auger electrons with energy greater than $250 \mathrm{eV}$ are shown in figure 3 . They are the result of $4 \mathrm{MeV}$ collisions of $\mathrm{C} 4+$ with $\mathrm{He}$ ( $3 \mathrm{a}$ ) and $\mathrm{Ne}$ ( $3 \mathrm{~b}$ ). Each peak is labeled and identified in table 2 . As shown there, the excited configurations are formed chiefly by capture into $n \geq 3$ shells of $1 \mathrm{~s} 2 \mathrm{~s}^{3} \mathrm{~S}$ ions. As $\mathbf{n}$ increases, it becomes more difficult to resolve the various transitions. Capture into $3 \mathrm{~s}$ and $3 \mathrm{p}$ (peak 1 ) is resolved from capture into $3 \mathrm{~d}$ (peak 2). However, for capture into $n=4$, we are unable to resolve capture into the various 41 subshells (peak 4). Also, capture into shells with $n \geq 5$ (region 6) are essentially unresolved. The Auger electron energy for the $\left(1 \mathrm{~s} 2 \mathrm{~s}^{3} \mathrm{~S}\right)$ nl series limit to $1 \mathrm{~s}^{2}{ }^{1} \mathrm{~S}$ decay occurs at $299 \mathrm{eV} 14$. Also identified in table 2 are the hypersatelite Auger transitions corresponding to $2 s^{2} 2 \mathrm{p} 2 \mathrm{P}$ and $2 \mathrm{~s} 2 \mathrm{p}^{2}{ }^{2} \mathrm{D}$ configurations decaying to either $1 \mathrm{~s} 2 \mathrm{~s}$ 1S or $1 \mathrm{~s} 2 \mathrm{~s}^{3} \mathrm{~S}$ (peaks $3,4,5$ ). The energies for these transitions were calculated by Chung ${ }^{13}$, and are reported here for the first time.

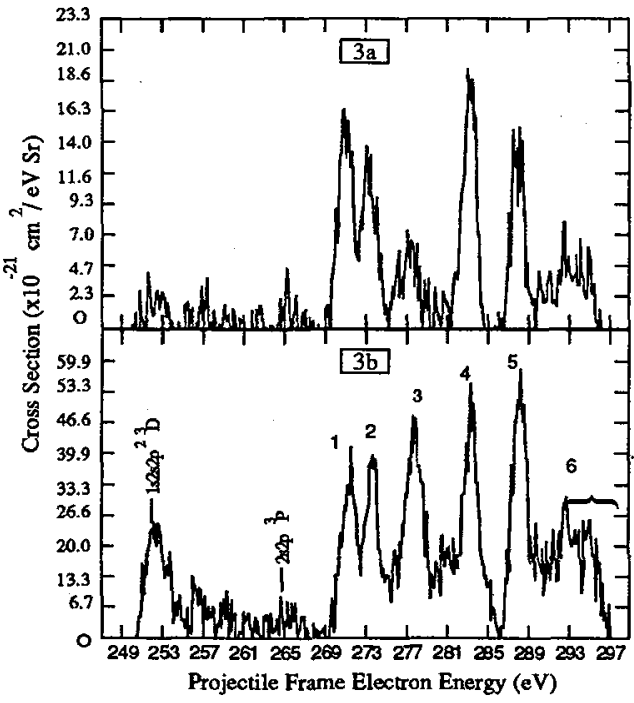

\begin{tabular}{|c|c|c|}
\hline & Table 2 & \\
\hline Peak & Excited - Final & Energy \\
\hline Number & Configuration & $(\mathrm{eV})$ \\
\hline 1 & $\left(1 s 2 s^{3} s\right) 3 s^{2} s-1 s^{21} s$ & 269.6 \\
\hline & $\left(1 s 2 s^{3} s\right) 3 p^{2} P-1 s^{21} s$ & 271.9 \\
\hline 2 & $\left(1 s 2 s^{3} S\right) 3 d^{2} D-1 s^{21} s$ & 274.3 \\
\hline & $2 s^{2} 2 p^{2} p \cdot 1 s 2 s^{1} S$ & 275.8 \\
\hline 3 & $\left(1 s 2 s^{1} s\right) 3 s, p, d-1 s^{21} s$ & $<279$ \\
\hline & $2 s^{2} 2 p^{2} p-1 s 2 s^{3} s$ & 281.3 \\
\hline & $\left(1 \mathrm{~s} 2 \mathrm{~s}^{3} \mathrm{~S}\right) 4 \mathrm{~s}, \mathrm{p}, \mathrm{d}, \mathrm{f}-1 \mathrm{~s}^{21} \mathrm{~s}$ & $<286$ \\
\hline 4 & $2 s^{2} 2 p^{2} D-1 s 2 s^{1} S$ & 282.4 \\
\hline 5 & $\left(1 \mathrm{~s} 2 \mathrm{~s}^{1} \mathrm{~s}\right) 4 \mathrm{~s}, \mathrm{p}, \mathrm{d}, \mathrm{f}-1 \mathrm{~s}^{21} \mathrm{~s}$ & $<291$ \\
\hline$J$ & $2 s^{2} 2 p^{2} D-1 s 2 s^{3} s$ & 287.9 \\
\hline$(1$ & Is $\left.2 s^{3} s\right)$ nl series limit $-1 s^{21} s$ & $<299$ \\
\hline
\end{tabular}

Figure 3 High resolution Auger electron production spectra of Carbon formed in $4 \mathrm{MeV}$ collisions of $\mathrm{C}^{4+}$ with $\mathrm{He}(\mathrm{Ba})$ and $\mathrm{Ne}(3 b)$. Table 2 Identification of Auger transitions for figure $3 a$ and $3 b$. The transitions in bold script are thought to be formed through RTE or NTE with incident $C^{4+}\left(1 s 2 s^{3} S\right)$, and their Auger decay energies were calculated by Chung 13 . Other transitions are identified in reference 14.

Figure 4 shows inferred capture cross sections into all $\mathrm{n} \geq 3$ shells of metastable $\mathrm{C} 4+$ ions. They were obtained by dividing production cross sections for all Auger electrons having energies between $\sim 269 \mathrm{eV}$ and $299 \mathrm{eV}$ by the metastable fractions given in table1. Although all of the excited configurations contributing to Auger production in this range of emission energies result from capture into metastables, the hypersatelite transitions also fall in this range. The doubly core excited configurations can be formed by $n=2$ capture into metastable ions accompanied by $1 s-2 s$ or $1 \mathrm{~s}-2 \mathrm{p}$ excitation such as occurs in either RTE or NTE. Indeed, the data shows an increase for all targets near the RTE resonance collisioin energy. 5. Discussion The experimental ratios for production of the $1 s(2 s 2 p 1 P) 2 P$ to $1 s\left(2 s 2 p{ }^{3} P\right) 2 P$ configurations at the various collision energies are given in table 1 . The $1 \mathrm{~s} 2 \mathrm{~s} 2 \mathrm{p} 2 \mathrm{P}$ is formed directly when a Helium electron is captured into the $2 \mathrm{p}$ orbital of a metastable ion. As discussed in the text, fractional parentage coefficients show that this ratio is 3.0 when a $2 p$

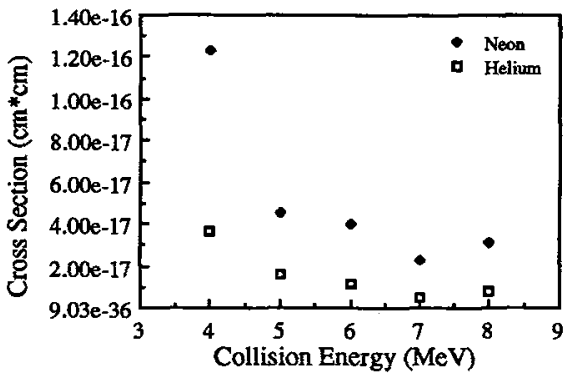

Figure 4 Inferred capture cross sections into all sub-shells with $n \geq 3$ by 1 s $2 s{ }^{3} S$ projectiles. Capture cross sections are obtained by dividing Auger production cross sections by the fraction of metastable ions in the incident projectile beam at each collision energy. 
electron is coupled into a $1 \mathrm{~s} 2 \mathrm{~s}{ }^{3} \mathrm{~S}$ ion, and $1 / 3$ when coupled into a $1 \mathrm{~s} 2 \mathrm{~s} 1 \mathrm{~S}$ ion. Our measured ratios range from 2.0 to 2.89 and indicate that $80 \%$ to $96 \%$ of the incident metastables are $1 \mathrm{~s} 2 \mathrm{~s}{ }^{3} \mathrm{~S}$.

Also shown in table 1 are the experimental production ratios for $1 \mathrm{~s}^{2} \mathrm{~s}^{2} 2 \mathrm{~S}$ and $1 \mathrm{~s}(2 \mathrm{~s} 2 \mathrm{p} 1 \mathrm{P}){ }^{2 \mathrm{P}}$ configurations. Based merely on the number of $2 s$ and $2 p$ vacancies in the incident $1 s 2 s{ }^{3} s$ ions (one for $2 s$, and six for $2 p$ ) and since $3 / 8$ of all $2 p$ capture into these ions results in the $1 \mathrm{~s}(2 \mathrm{~s} 2 \mathrm{p} 1 \mathrm{P}) 2 \mathrm{P}$ a ratio of $1 \mathrm{~s} 2 \mathrm{~s}^{2} 2 \mathrm{~S}$ to $1 \mathrm{~s}(2 \mathrm{~s} 2 \mathrm{p} 1 \mathrm{P}){ }^{2} \mathrm{P}$ production of .444 is expected. The experimental values are lower than .444 indicating that capture into the half full $2 \mathrm{~s}$ subshell is strongly suppressed at low collision energies. This suppression is the result of the repulsive potential between the spectator and captured electrons. The data indicates that the repulsion becomes less important as the collision velocity is increased. At $3 \mathrm{MeV}$ the collision velocity is about equal to the Bohr orbital velocity of the $2 \mathrm{~s}$ electron, while at $15 \mathrm{MeV}$ it is about $2.84 \mathrm{v}_{2 \mathrm{~s}}$.

Since the spin-orbit interaction is negligible for Carbon, the orientation of the total spin vector (S) for electrons in the incident ion and that of the captured electron (s) should not effect the capture probability. For capture into a $2 p$ orbital of $1 s 2 s{ }^{3} \mathrm{~S}$ ions, 1s $2 \mathrm{~s} 2 \mathrm{p} 4 \mathrm{P}$ and $1 \mathrm{~s} 2 \mathrm{~s} 2 \mathrm{p}{ }^{2} \mathrm{P}$ configurations should be produced with equal probability. Since the $1 \mathrm{~s} 2 \mathrm{~s} 2 \mathrm{p} 4 \mathrm{P}$ $1 \mathrm{~s}^{2}$ 1S decay requires a spin flip, its mean life (eg. $t=117 \mathrm{nsec}$ for $\left.{ }^{4} \mathrm{P}_{5 / 2}\right)^{15}$ is greater than the transit time for ions over the spectrometer viewing region and only a fraction of the $4 \mathrm{P}$ ions produced in this region decay before the ion exits. This is clearly shown in figure $1 \mathrm{~b}$ where the $1 \mathrm{~s} 2 \mathrm{~s} 2 \mathrm{p} 4 \mathrm{P}-1 \mathrm{~s}^{2} 1 \mathrm{~S}$ appears as the weakest transition. In order to obtain absolute production cross sections, the measured intensity for this transition must be divided by an efficiency factor calculated at each collission energy:

$$
\varepsilon_{1 \mathrm{~s} 2 \mathrm{~s} 2 \mathrm{p}{ }^{4} \mathrm{p}-1 \mathrm{~s}^{21} \mathrm{~s}}=\int_{x_{0}}^{x_{0}+\mathrm{x}_{1}} \frac{\left(1-\mathrm{e}^{-\mathrm{x} / v \tau}\right)}{\mathrm{x}_{1}} d x
$$

where $x_{0}$ is the distance from the entrance aperture of the target cell to the start of the viewing region, $x_{1}$ is the length of the viewing region and $v$ is the collision velocity. Using calculated values for ${ }^{4} \mathrm{P}_{5 / 2,3 / 2,1 / 2}-{ }^{1} \mathrm{~S}_{0}$ lifetimes 15 and assuming a statistical population for the multiplets, this correction gives experimental $4 \mathrm{P}$ production cross sections that are significantly larger than $2 \mathrm{P}$ production cross sections. This indicates that the $1 \mathrm{~s} 2 \mathrm{~s} 2 \mathrm{p} 4 \mathrm{P}$ may be fed by cascades. Work is in progress to account for this.

Inferred cross sections for capture into $\mathrm{n} \geq 2$ shells of $\mathrm{K}$-vacancy bearing ions in collisions with $\mathrm{H}_{2}$, He and $\mathrm{Ne}$ targets are shown in figure 2a. The average ratio of these cross sections for $\mathrm{Ne}$ and $\mathrm{He}$ is 5.6 indicating an approximate scaling of capture with the number of target electrons $\left(\mathrm{N}_{\mathrm{Ne}} / \mathrm{N}_{\mathrm{He}}=5\right)$. The trend with energy of the data agrees with the semiclassical calculation for $\mathrm{He}$ electron capture by $\mathrm{C}^{4+}$ ions, but the calculation had to be multiplied by 4.5 . This is expected since the data represents capture into $1 \mathrm{~s} 2 \mathrm{~s}{ }^{3} \mathrm{~S}$ configurations and the calculation assumes a structureless projectile with nuclear charge of 4+ which underestimates the true projectile potential in the region between the projectile nucleus and the spectator electron. As a result, the calculation systematically underpredicts the capture probability for small impact parameters. Other failures of the calculation are the assumption of a straight line trajectory for the projectile in the rest frame of the Helium atom, and the inability to predict partial cross sections for capture into particular nl orbitals. A calculation which would predict partial capture cross sections would be very useful in the various transfer excitation calculations shown in figure $2 \mathbf{b}$.

The primary sources of systematic error in our data are uncertainty in the value of the fraction of metastable ions in the incident beam and the assumption of isotropic Auger electron emission. Isotropic emission is assumed in transforming our measured projectile Auger electron yields into absolute production cross sections. Since our measurements were taken at $\sim 10^{\circ}$ with respect to the ion beam emerging from the target cell $\left(\sim 20^{\circ}\right.$ in the projectile rest frame) any allignment of excited configurations with the collision axis would result in our cross sections being too large. Preliminary angular studies of the Auger decay of excited states formed through RTE for the $\mathrm{O}^{5+}+\mathrm{He}$ system show a strong decrease in intensity as the observation angle is increased. We estimate that the absolute uncertainty in the metastable fraction values given in table 1 to be $\pm 10 \%$.

In figure $2 \mathrm{~b}$ we show the $1 \mathrm{~s} 2 \mathrm{p}^{2} 2 \mathrm{D}-1 \mathrm{~s}^{2}$ is Auger production cross sections and various calculations for capture into $2 \mathrm{p}$ accompanied by excitation. A maximum in the data at $5 \mathrm{MeV}$ is present for all targets and agrees with the RTE resonance collision energy: $E_{R T E}=E_{A u g}\left(1 s 2 p^{2} 2 \mathrm{D}-1 s^{2} 1 S\right) M_{C} / m_{e}=5.3 \mathrm{MeV}$. The resonance width of the scaled RTE calculation describes the Helium target data well, showing that the impulse approximation 6 is valid for the Carbon - Helium collision system. Near the $4 \mathrm{MeV}$ collision energy the RTE and NTE probabilities are nearly equal and the measured cross section seems to be significantly lower than that predicted by summing the various calculations. It would be interesting to obtain more data in this region to see if there is destructive interference between RTE, NTE, and TE.

In the case of $1 \mathrm{~s} 2 \mathrm{~s} 3 \mathrm{~S}$ ions, electron capture into $\mathrm{n}=2$ accompanied by $1 \mathrm{~s}-2 \mathrm{p}$ excitation results in either a $2 \mathrm{~s}^{2} 2 \mathrm{p} 2 \mathrm{P}$ or $2 s 2 p^{2} 2 \mathrm{D}$ doubly core excited configuration. The calculated Auger electron energies for the hypersatelite transitions that result when these ions decay to either $1 \mathrm{~s} 2 \mathrm{~s} 1 \mathrm{~S}$ or $1 \mathrm{~s} 2 \mathrm{~s} 3 \mathrm{~S}$ are shown in bold print in table 2 . A maximum in the production of the doubly core excited configurations through RTE would be expected at: $E_{R T E}(2 P)=\left(M_{C} / m_{e}\right)(275.8 \mathrm{eV})=6.1 \mathrm{MeV}$ and $E_{R T E}$ $=\left(\mathrm{M}_{\mathrm{C}} / \mathrm{m}_{\mathrm{e}}\right)(282.4 \mathrm{eV})=6.2 \mathrm{MeV}$. Inclusive cross sections for capture into $\mathrm{n} \geq 3$ of $1 \mathrm{~s} 2 \mathrm{~s}^{3} \mathrm{~S}$ ions as well as capture into $\mathrm{n}=2$ accompanied by 1s-2s or 1s-2p excitation (RTE and NTE) are shown in figure 4. An increase in the data near $6 \mathrm{MeV}$ is seen for all targets and is thought to be due to RTE. The spectra shown in figure $3 a$ (Helium target) and $3 b$ (Neon target) were measured at a collision energy of $4 \mathrm{MeV}$. At this collision energy, the probability for production of doubly core excited configurations through NTE is maximum. For both targets, nearly all of the intensity in peaks 3 and 4 are due to 
hypersatelite decays to $1 \mathrm{~s} 2 \mathrm{~s} 1 \mathrm{~S}$. The only other likely source of Auger electrons at these energies would be from decays of (1s2s $1 S) 31$ or $\left(1 s 2 s^{1 S}\right) 41$ to $1 s^{2} 1 \mathrm{~S}$. This is unlikely since those excited configurations are formed by electron capture into $n=3$ or $n=4$ of $1 \mathrm{~s} 2 \mathrm{~s}^{1 \mathrm{~S}}$ projectiles and we already know that only $\sim 10 \%$ of the incident metastables are $1 \mathrm{~s} 2 \mathrm{~s}$ 1S. Finally, a propensity for forming $2 s^{2} 2 \mathrm{p} 2 \mathrm{P}$ ions for collisions with Neon is seen (peaks 2 and 3 ).

We are gratefull to Dr. Joseph K. Swenson for experimental advice and assistance, and to Prof. K.T. Chung and B. F. Davis for calculating the transition energies for the hypersatelite transitions. We would also like to thank professors $N$. Stolterfoht and P. Richard for useful comments and illuminating discussions during the course of this work. Early stages of this work were supported by the Division of Chemical Sciences, U.S. Department of Energy, under contract No.

De-AS05-78ER06027.

\section{References}

1 T.R. Dillingham, J. Newcomb, James Hall, Phillip L. Pepmiller and Patrick Richard, Phys. Rev. A 29, 3029 (1984) also, T.R. Dillingham, Ph. D. Thesis, (Kansas State University 1983)

2 R. Mann, Phys. Rev. A 35, 4988 (1987) also, H. Cederquist, L.H. Andersen, A. Barany, P. Hvelplund, H. Knudsen, E.H. Nielsen, J.O.K. Pedersen, and J. Sorensen, J. Phys. B 18, 3951 (1985)

3 D. Brandt, Nucl. Instr. and Meth. 214, 93 (1983) for additional NTE references, see also: M.W. Clark, J.K. Swenson, S.M. Shafroth, Phys. Rev. Let. , (1985) and P.L. Pepmiller, P. Richard, J. Newcomb, J. Hall, T.R. Dillingham, Phys. Rev. A 31,734 (1985)

4 J.K. Swenson et. al., Phys Rev Lett 57, 3042 (1986)

5 A. Itoh, T.J.M. Zouros, D. Schneider, U. Stettner, W. Zeitz, and N. Stolterfoht, J. Phys. B 18, 4581 (1985)

6 D. Brandt, Phys. Rev. A 27, 1314 (1983)

7 J.K. Swenson, Nucl. Instr. and Meth. B $10 / 11,899$ (1985) Note new value of acceptance angle: $0.80^{\circ}$

8 J.K. Swenson, J.M. Anthony, M. Reed, M. Benhenni and S.M. Shafroth, Nucl. Instr. and Meth. B 24/25, 184 (1987)

9 H. Knudsen, H.K. Haugen, and P. Hvelpund, Phys. Rev. A24, 2287 (1981)

10 See for example: C.D.H. Chisolm, A. Dalgamo, and F.R. Innes, in Advances in Atomic and Molecular Physics, edited by D.R. Bates and I. Estermann (Academic, New York, 1969), Vol. 5, pp. 297-335

11 T.L. Mcabee, Nucl. Instr. and Meth. 214, 89 (1983)

12 D.J. McLaughlin, private communication 1987, for method see: D.J. McLaughlin, Y. Hahn, Phys. Lett. $88 \mathrm{~A}, 394$ (1982)

13 K.T. Chung and B.F. Davis, private communication 1987, see: Kwong T. Chung, Phys. Rev. A20, 1743 (1979)

14 D. Schneider et. al., Phys. Rev, A15, 926 (1977)

15 M.H. Chen, B. Crasemann, and H. Mark, Phys. Rev. A27, 544 (1983) 